\title{
Perancangan Interior Kantor Pusat PT Pelindo 3 (Persero) dengan Penerapan Konsep Seni Nusantara untuk Peningkatan Efisiensi dan Produktifitas Kerja
}

\author{
Thomas Ari Kristianto ${ }^{1}$, Caesario Ari Budianto ${ }^{2}$, Okta Putra Setio Ardianto ${ }^{3}$ \\ ${ }^{1,2}$ Dosen Jurusan Desain Interior Institut Teknologi Sepuluh Nopember, \\ ${ }^{3}$ Desainer Interior GriyanggitaRumah Desain, Surabaya \\ 1'thomasjawa@prodes.its.ac.id, ${ }^{2}$ caesario101@gmail.com , ${ }^{3}$ oktaputra07@gmail.com
}

\begin{abstract}
ABSTRAK
Peningkatan efisiensi dan produktivitas kerja adalah kebutuhan setiap perusahaan, tak terkecuali PTPelindo 3 (Persero). Tantangan kerja yang semakin besar membutuhkan penyeimbang agar seluruh karyawan dapat mengoptimalkan diri dengan resiko stress yang lebih rendah. Desain interior kantor yang mengakomodasi kebutuhan kerja kantor modern dan menerapkan konsep seni dapat menjadi solusi permasalahan tersebut. Penerapan seni diharapkan menyentuh sisi emosi sehingga memberikan efek relaksasi.

Metode perancangan menggunakan pendekatan user oriented dengan karyawan dari jajaran staf kerja hingga tingkatan senior manajer PTPelindo 3 (Persero) sebagai user perancangan desain interior. Penggalian data desain dilakukan dengan cara wawancara dan pengamatan lapangan langsung. Data yang didapatkan diolah dan dijadikan pertimbangan pada proses desain yang dilaporkan secara berkala. Hasil perancangan selanjutnya di-review menggunakan literatur-literatur ilmiah terkait untuk mengukur tingkat keberhasilan perancangan.

Dari hasil pengumpulan data pra-desain didapatkan masalah utama perancangan adalah layout yang belum sesuai alur kerja, kebutuhan penyimpanan berkas, pengembangan kantor dan elemen estetika. Perancangan interior kantor difokuskan pada penyelesain masalah utama tersebut. Hasil perancangan adalah perbaikan layout, desain area kerja dan penyimpanan pada area kerja staf. Selain itu diberikan tambahan ruang baru sesuai kebutuhan terkini perusahaan dan pemberian elemen seni rupa pada banyak bagian interior kantor. Elemen seni rupa dipilih untuk diterapkan pada interior dengan pertimbangan efek visual dapat dengan mudah diapresiasi oleh seluruh tingkat karyawan perusahaan.
\end{abstract}

Kata Kunci : Seni, Efisiensi, Kantor

\section{ABSTRACT}

Increased efficiency and productivity of work are the needs of every company, not least PT.Pelindo 3 (Persero). The greater challenge of working that require a counterweight so that all employees can optimize itself with a lower risk of stress. Office interior design that accommodates the needs of modern office work and apply the concept of art can be a solution to these problems. Implementation is expected to touch the emotional side of art so as to provide a relaxing effect.

The design method uses user oriented approach with employees from the ranks of the working staff up to senior level managers PT.Pelindo 3 (Persero) as the user of the interior design. Excavation of design data by interview and direct field observations. The data obtained were processed and taken into consideration in the design process are reported regularly. The next design results were reviewed using relevant scientific literature to measure the success rate design.

From the results of pre-designed data collection obtained main problem is the layout design that does not meet the workflow, file storage needs, the development of office and aesthetic elements. Interior design office focused on completion of the main problems. The results of the design is an improved layout, design work and storage areas on the staff work area. Additionally provided additional new space according the company's current needs and providing elements of art in many 
parts of the interior of the office. Elements of art have to be applied to the interior with consideration of visual effects can be easily appreciated by all levels of employees.

Keywords : Art, Efficiency, Office

\section{PENDAHULUAN}

PT Pelindo 3 (Persero) adalah Badan Usaha Milik Negara yang memiliki bisnis inti pada pengelolaan pelabuhan. Hingga saat ini PT Pelindo 3 (Persero) mengelola 43 pelabuhan di wilayah Indonesia timur dan memiliki 16 kantor cabang dengan kantor pusat terletak di Surabaya. Kondisi tersebut membuat seluruh karyawan kantor ppusat PT Pelindo 3 (Persero) dituntut untuk memiliki performa prima dalam menjalankan aktifitas perkantorannya.

Sebagai pendukung peningkatan efisiensi kerja yang berakibat pada performa kerja yang prima, desain interior kantor yang sanggup mendukung kegiatan kantor menjadi kebutuhan yang mendesak untuk direalisasikan. Perancangan interior diperlukan untuk mencapai tujuan tersebut. Diharapkan dari perancangan interior tersebut mampu memberikan usulan desain interior kantor yang ideal pada kantor pusat PT Pelindo 3 (Persero).

\section{METODE}

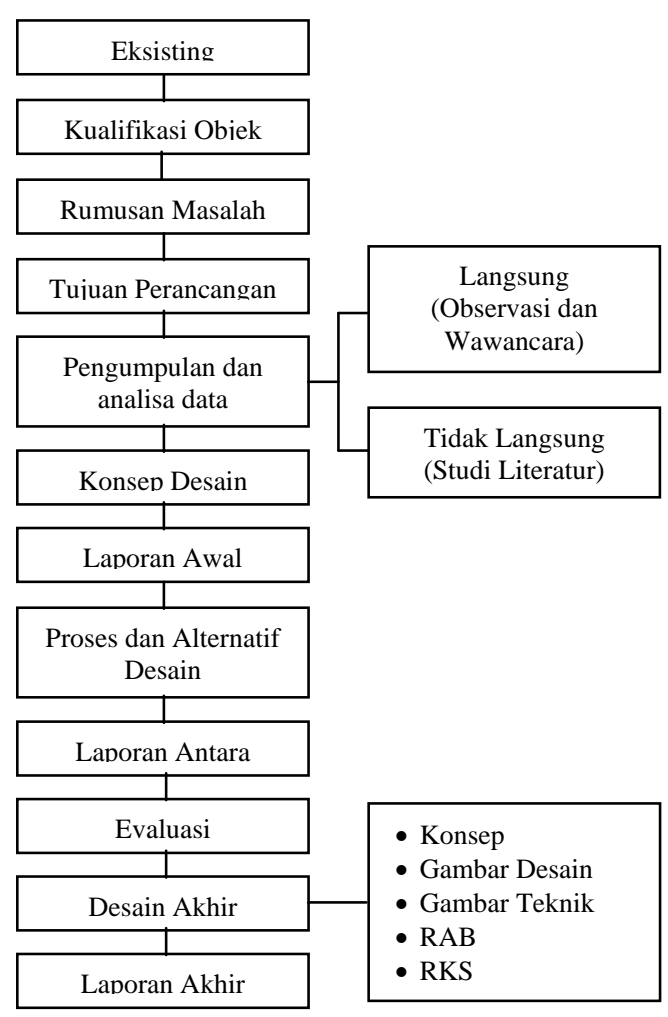

Gambar 1. Bagan Metode Perancangan Sumber : Konstruksi Penulis (2015)

Metode perancangan dilakukan dengan sistematis, langkah pertama menentukan sasaran, variabel, dan kriteria desain. Langkah selanjutnya memperhatikan analisa data menyeluruh (langsung dan tidak langsung), dan mensintesa konsep desain serta mengevaluasinya dengan studi literatur (Gambar 1). 


\section{STUDI LITERATUR}

Penataan ruang kantor merupakan salah satu faktor penting yang dapat mempengaruhi kinerja pengguna yang berada didalamnya. Tata ruang yang baik dan sesuai dengan kebutuhan pengguna, akan bermanfaat dan memperlancar tata usaha sebuah perkantoran.

Ruang kerja yang efektif adalah ruang kerja yang kondusif dan sesuai pada tempat dan gunanya. Tren pekerjaan di masa depan perlu diperhatikan dalam perencanaan tata ruang keja (Gustafsson, 2002), diantaranya adalah:

1. Pekerjaan berbasis tim (work-based teams), sangat sesuai dengan lingkungan yang selalu berubah-ubah atau tidak menentu secara dinamis. Kantor berkonsep tata ruang terbuka (open space plan) lebih sesuai sehingga dapat digunakan untuk ruang rapat secara optimal.

2. Telecomutting, tren pegawai dalam pelaksanaan pekerjaannya dilakukan diluar kantor. Hal ini perlu diperhatikan pula agar tetap dapat menjaga produktivitas kerja, sehingga diperlukan adanya ruangan atau pembagian area kerja tersendiri bagi konsentrasi pekerjaan mereka.

3. Hoteling, ditujukan bagi pegawai yang dipekerjakan di lapangan. Biasanya pegawai hanya akan datang sesekali waktu dan untuk beberapa saat saja ke kantor. Hal ini membutuhkan ruangan kantor yang optimal.

Terdapat 6 azas pokok dalam tata ruang instansi yang baik (Muther, 1955), diantaranya adalah:

1. Jarak terpendek, memungkinkan proses penyelenggaraan suatu pekerjaan dapat ditempuh dengan jarak sependek mungkin.

2. Rangkaian kerja, menempatkan para pegawai dan alat-alat kantor menurut rangkaian yang sejalan dengan urutan-urutan penyelesaian pekerjaan.

3. Penggunaan segenap ruang, mempergunakan sepenuhnya semua ruang yang ada. Ruang itu tidak hanya yang berupa luas lantai saja (ruang datar), melainkan juga ruang vertikal ke atas maupun ke bawah sehingga kemungkinan ruang tidak terpakai kecil.

4. Perubahan susunan tempat kerja, tata raung yang dapat diubah atau disusun kembali dengan baik, lepas dari kesulitan atau tidak memakan biaya yang besar.

Dalam merancang tata ruang kerja yang efektif ada beberapa prinsip yang harus diperhatikan (Martinez, 1990 dan Quible, 2001) :

1. Menganalisis hubungan antara peralatan, informasi, dan pegawai dalam alus kerja.

2. Mengondisikan arus kerja agar bergerak dalam bentuk garis lurus dan meminimalisir kemungkinan terjadinya crisscossing dan backtracking.

3. Pegawai maupun tim kerja yang melakukan pekerjaan serupa harus ditempatkan dalam area yang berdekatan.

4. Pegawai maupun divisi yang berhubungan dengan publik harus ditempatkan berdekatan dengan pintu masuk kantor.

5. Pegawai maupun tim kerja yang membutuhkan konsenterasi harus ditempatkan di ruang kerja yang suasananya lebih tenang.

6. Alokasi ruang harus berdasarkan posisi, pekerjaan yang dilakukan, dan peralatan khusus yang diperlukan masing-masing individu.

7. Furnitur dan peralatan harus sesuai dengan kebutuhan.

8. Lorong ahrus nyaman dan lebaruntuk mengantisipasi pergerakan yang efisien dari pekerja.

9. Pertimbangan keamanan harus diberikan prioritas tinggi.

10. Area terbuka yang besar lebih efisien dibandingkan ruangan kecil yang tertutup. 
11. Provisi yang tepat bagi pencahayaan, dekorasi, AC, kelembaban dan kontrol suara.

12. Memperhatikan kebutuhan perluasan kantor di masa datang.

13. Pekerjaan harus datang pada pegawai, bukan sebaliknya.

Wylie (1958) membedakan tataruang menjadi dua macam, yaitu :

1. Tata ruang terpisah-pisah (tertutup), susunan tataruang ini dibagi dalam kamar-kamar atau ruangan terpisah. Kamar atau ruangan ini pada umumnya dipisahkan berdasarkan pelaksanaan fungsi tiap-tiap seksi atau bagian.

2. Tata ruang terbuka (open space plan), ruang pimpinan dan para pegawainya berada dalam satu ruangan terbuka tanpa adanya sekat pemisah.

Dari kedua jenis tata ruang tersebut, sebagian para ahli menambahkan bahwa ada jenis yang ketiga yaitu tata ruang gabungan, dimana kombinasi antara tataruang terbuka dan tertutup. Untuk tetap menjaga wibawa pimpinan maka dibuatlah satu ruang kerja untuk seorang pimpinan. Adapun para pegawai ditempatkan dalam satu ruang kerja sehingga sistem pengawasan lebih mudah untuk dilakukan.

Faktor-faktor yang mempengaruhi tata ruang kerja, diantaranya adalah:

1. Cahaya, penerangan yang cukup dan memancar dengan tepat akan menambah efisiensi kerja para pegawai. Karena mereka dapat bekerja dengan lebih cepat, lebih sedikit membuat kesalahan, dan matanya tidak lekas menjadi lelah. Banyak ketidakberesan pekerjaan tatausaha disebabkan oleh penerangan yang buruk, misalnya ruangan terlampau gelap atau pegawai-pegawai harus bekerja dibawah penerangan yang menyilaukan.

2. Warna, bersama-sama dengan cahaya, warna merupakan faktor yang penting untuk memperbesar efisiensi kerja para pegawai. Khususnya warna akan mempengaruhi keadaan jiwa mereka. Dengan memakai warna yang tepat pada dinding ruangan dan alat-alat lainya, kegembiraan dan ketenangan bekerja para pegawai akan terpelihara. Selain itu warna yang tepat juga akan mencegah kesilauan yang mungkin timbul karena cahaya yang berlebihan.

3. Udara, mengenai faktor udara ini, yang terpenting adalah suhu udara dan banyaknya uap air pada udara itu sendiri (kelembapan)

4. Suara, ruangan kantor sejauh mungkin dijauhkan dari sumber kebisingan. Jika perlu digunakan bahan peredam suaru pada langit atau dinding ruangan.

\section{PEMBAHASAN}

Perancangan desain interior kantor pusat PT Pelindo 3 (Persero) meliputi ruang-ruang eksisting lantai 1 dan 2, serta penambahan bagian belakang gedung A. Secara umum perancangan terdiri dari dua jenis, yaitu bagian publik dan kantor. Pada pembahasan ini dipaparkan sampel dari kedua jenis peracangan tersebut. Lobi mewakili bagian publik dan ruang kantor subdit umum dan SDM lantai mewakili bagian perancangan kantor.

\section{A. Analisa Eksisting}

Penyusunan konsep utama peracangan didukung oleh data analisa bangunan saat ini dengan metode pengamatan lapangan dan wawancara dengan pengguna bangunan. Dari kedua tahapan metode tersebut dihasilkan inti dari kondisi eksisting adalah:

1. Layout saat ini bisa lebih diefisiensikan.

2. Dibutuhkan spesifikasi fungsi lounge.

3. Diperlukan efisiensi ruang pengembangan dan penyimpanan berkas.

4. Diperlukan optimalisasi pencahayaan dan penghawaan alami ruang. 
5. Diperlukan penyesuaian kelistrikan dengan alur kerja (lampu, data, saklar, ac, stop kontak).

6. Diperlukan penyegaran nuansa interior untuk peningkatan daya dukung kerja.

\section{B. Konsep Perancangan}

Konsep perancangan berpatokan pada visi perusahaan mengenai integrasi. Konsep perancangan adalah integrasi aspek fisik dan jiwa desain interior, yaitu perancangan integral antara aspek teknis dan seni ruangan kantor. Implementasi aspek teknis adalah penggunaan sistem ramah lingkungan berbasis hemat energi dan aspek seni adalah penggunaan elemen interior seni publik (patung, instalasi dan panel seni) bertemakan budaya seni visual nusantara. Langgam desain yang digunakan adalah langgam modern. Implementasi dari konsep tersebut adalah:

\section{1) Konsep Warna}

Konsep warna (Gambar 2) yang diterapkan adalah warna citra perusahaan dipadu dengan warna netral dengan nuansa netral. Warna aksen diambil warna biru dan kreasi beberapa turunan warna biru. Warna biru adalah perlambang visi PTPelindo 3 (Persero) untuk memberi pelayanan yang prima. Warna nuansa diambil dari kelompok warna netral. Warna yang digunakan adalah turunan warna abu-abu berpadu coklat.

2) Konsep Lantai

Pola lantai organik di bagian publik dan sebagian bagian sirkulasi. Warna dominan perpaduan warna netral. Material menggunakan lantai batu alam buatan pada ruang publik dan karpet pada kantor

3) Konsep Dinding

Pola bentukan organik pada bagian penebalan dinding. Warna dominan warna aksen pada modifikasi dinding.Aplikasi dinding seni pada bagian publik dan dinding penyemangat pada bagian kantor.

4) Konsep Plafon

Lebih banyak pola polos dengan aksen drop ceiling berbentukan organik dengan warna netral. Menggunakan sistem plafon gantung dengan material dominan papan gypsum dan acoustic tile.

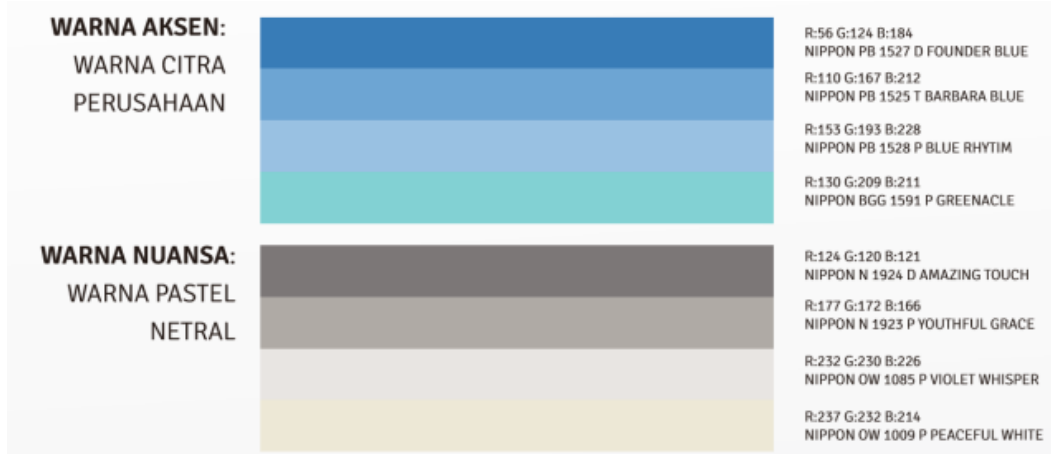

Gambar 2. Visual Konsep Warna Perancangan

Sumber : KonstruksiPenulis (2015)

5) Konsep Hirarki Fasilitas Kantor

Fasilitas kantor yang digunakan pada masing-masing tingkatan jabatan berbeda menyesuaikan kompleksitas kerjanya. Sebagai contoh luasan kerja workstation pada staf 
lebih kecil dan sederhana daripada asisten manajer. Gambar 3 memberikan ilustrasi perbedaan desain dan fasilitas workstation,
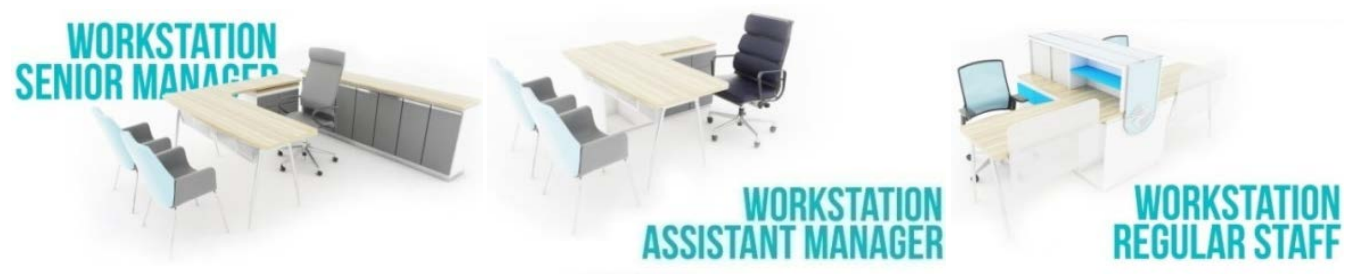

Gambar 3. Desain workstation berdasarkan hirarki kerja Sumber :Dokumentasi Penulis (2015)

\section{Desain Interior Lobi}

Pada lobi perubahan yang tampak signifikan dibandingkan kondisi eksisting adalah peletakan meja penerima lebih dekat ke pintu masuk utama. Tata letak dibuat sedemikian rupa sehingga membagi sirkulasi pengunjung luar dan karyawan ke alur yang berbeda. Seperti ilustrasi pada gambar 4, sirkulasi pengunjung lurus ke tengah ruangan diterima meja penerima dan bagian elevator sebagai orientasi ruang sedangkan karyawan menggunakan sirkulasi pada bagian pinggir ruang menuju bagian kantor masing-masing.

Kesan yang ditampilkan adalah mewah dan hangat (Gambar 5). Dengan tujuan tersebut pada lobi digunakan material batuan alam dengan permukaan mengkilap dan warna pastel hangat.

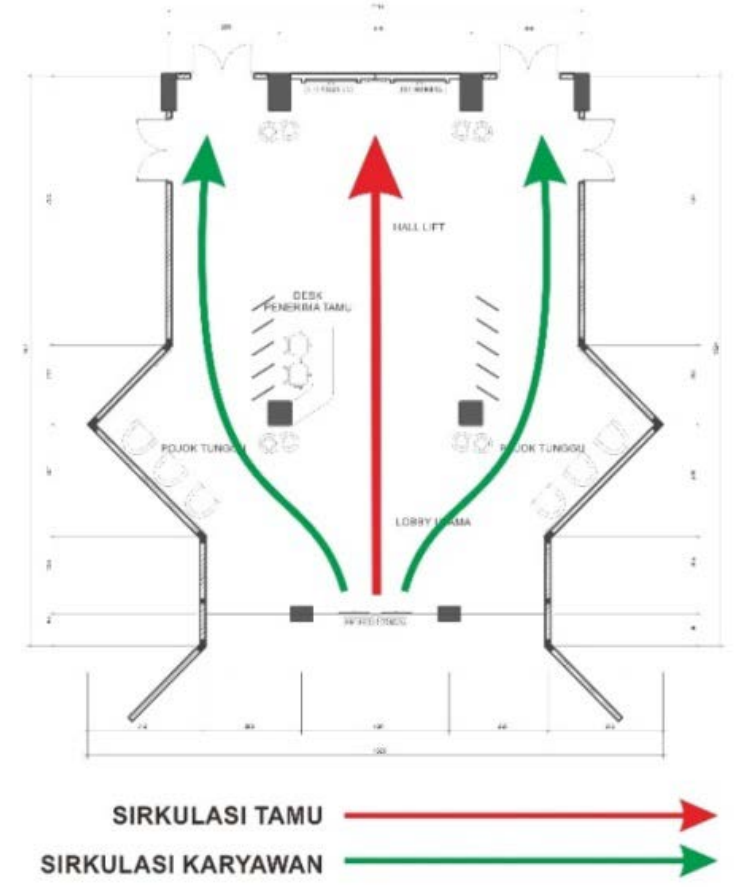

Gambar 4. Layout Ruang Lobi

Sumber : Dokumentasi Penulis (2015)

Untuk penerapan sentuhan seni nusantara pada lobi digunakan lampu gantung berbahan anyaman rotan dengan bentukan organik lengkung. Rotan mewakili material khas nusantara dan bentukan organik lengkung memberikan visualisasi bentuk kepulauan sebagai identitas khas nusantara (Gambar 6). 


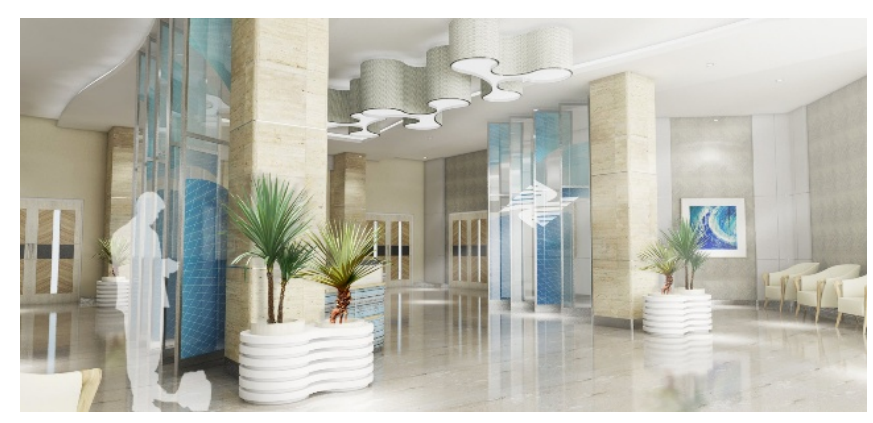

Gambar 5. Gambar Desain Lobi

Sumber : Dokumentasi Penulis (2015)

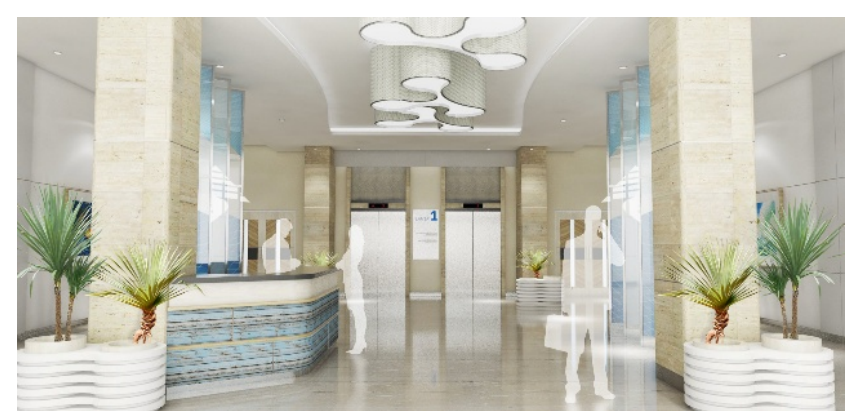

Gambar 6. Gambar Desain Lobi dengan Tampak Lampu Gantung Berbahan Anyaman Rotan Sumber : Dokumentasi Penulis (2015)

\section{Desain Interior Ruang Kerja Subdit Umum}

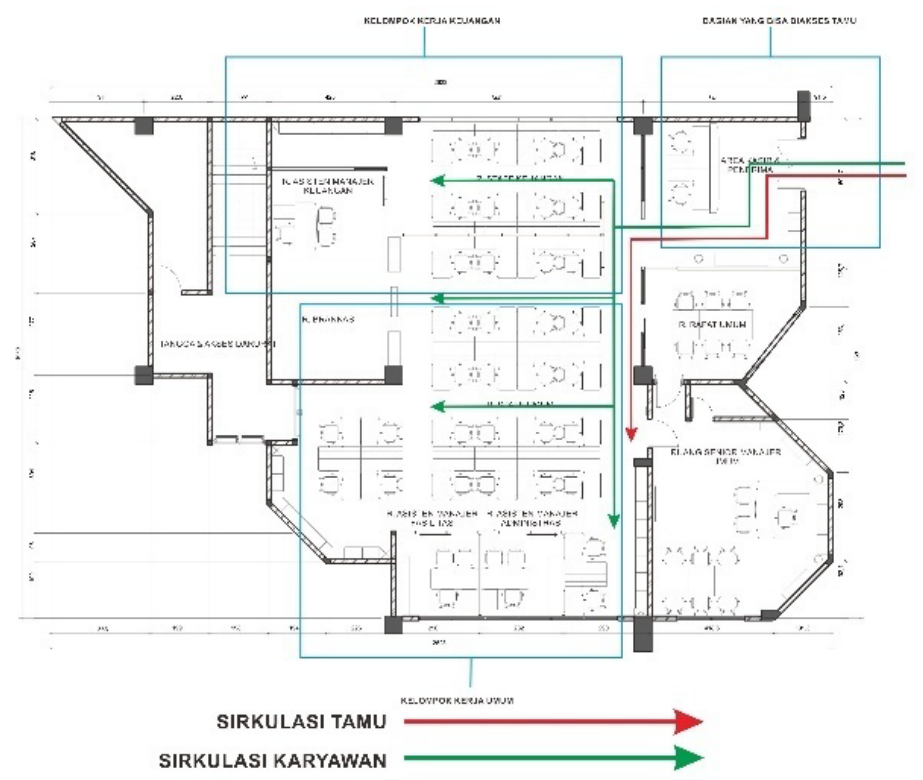

Gambar 7. Layout Ruang Kerja Umum

Sumber : Dokumentasi Penulis (2015)

Ruang kerja subdit umum terdiri dari ruang kerja staf umum, 4 asiten manajer umum, staf keuangan dan satu asisten manajer keuangan. Layout disusun agar masing-masing kelompok staf mengumpul sesuai jenis stafnya dan mengelompok mendekati masing-masing asisten manajer. Hal ini dilakukan agar sirkulasi staf efektif dalam berkoordinasi dengan hirarki kerjanya. Seperti yang terlihat pada gambar 7, masing-masing staf mengelompok sesuai lingkup kerja. 
Ruang kerja staf menggunakan sistem open plan untuk mengefisienkan luasan kantor agar mencukupi terhadap kebutuhan jumlah staf. Kelebihan sistem ini ruang menjadi lapang dan efisien namun terdapat resiko kebisingan karena kegiatan kerja. Resiko itu diminimalisir dengan penggunaan plafon akustik. Pada ruang asistem manajer dibuat sistem semi open plan dengan partisi pendek untuk mempermudah koordinasi dengan staf sedangkan pada senior manajer digunakan sistem tertutup untuk pembeda hirarki kerja sekaligus tuntutan kerja yang mengharuskan ada batas penutup.

Seperti yang terlihat pada gambar 8, suasana sistem open plan akan membuat ruangan lebih lapang dan membentuk perilaku saling berinteraksi antar staf. Hal ini mengefisienkan pola kerja karena komunikasi lebih terbuka antar rekan kerja. Kesan yang ingin ditampilkan adalah kesan modern, bersih dan lapang seperti terlihat pada gambar 9.

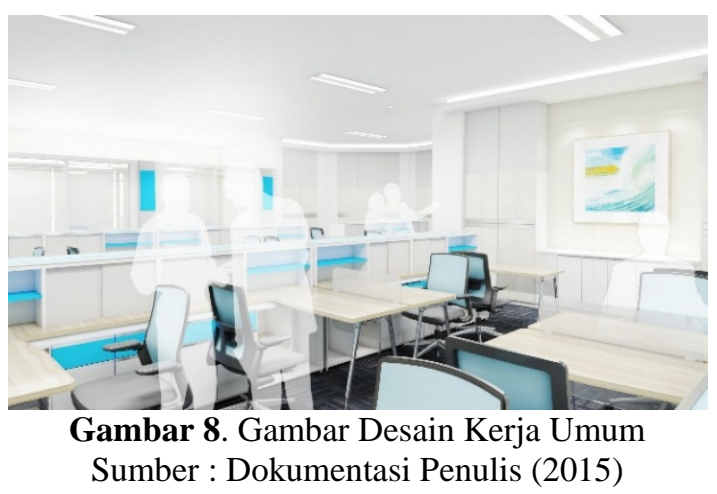

\section{KESIMPULAN}

Perancangan desain interior gedung A kantor pusat PT Pelindo 3 (Persero) dapat mecapai tujuan yaitu mendorong efisiensi kerja pengguna kantor dengan pendekatan penyelesaian masalah dengan solusi desain sebagai berikut:

1. Memberikan perubahan tata letak (layout) ruangan dengan fokus pada pembagian sirkulasi pengunjung dan karyawan kantor.

2. Menggunakan desain furnitur dengan fokus pada kemampuan penyimpanan berkas yang lebih efisien.

3. Penerapan sentuhan benda seni publik bertema budaya nusantara untuk memberikan nuansa relaksasi sekaligus penonjolan identitas perusahaan.

\section{DAFTAR PUSTAKA}

[1] Neufert, Ernst. (1980). Architects’ Data. New York: John Wiley \& Sons.

[2] De Chiara, Joseph. (1992). Time-Saver Standards for Interior Design and Space Planning. Singapore: Mc Graw-Hill, Inc.

[3] Laurens, Joyce Marcella. (2005). Arsitektur dan Perilaku Manusia. Jakarta: PT. Grasindo.

[4] Wylie, Harry L. (1958). Office Management Handbook. New York: Ronald Press.

[5] Gie, The Liang. (2007). Administrasi Perkantoran Modern. Yogyakarta: Liberty Yogyakarta.

[6] Sukoco, Badri Munir. (2006). Manajemen Administrasi Perkantoran Modern. Jakarta: Erlangga. 